\title{
Neuropeptide $Y$ modulates fear and fear extinction in distinct nuclei of the amygdala
}

\author{
Ramon O Tasan 1*, Dilip Verma', Mario Mietzsch², Regine Heilbronn², Herbert Herzog ${ }^{3}$, Günther Sperk' \\ From 18th Scientific Symposium of the Austrian Pharmacological Society (APHAR). Joint meeting with the \\ Croatian, Serbian and Slovenian Pharmacological Societies. \\ Graz, Austria. 20-21 September 2012
}

\section{Background}

Fear and anxiety are integrated in the amygdaloid nuclei and involve the interplay of the amygdala with various other brain areas. Neuropeptides play a critical role in regulating these processes. Neuropeptide Y (NPY) is highly expressed in limbic brain areas, including the amygdala. Depending on the receptor subtypes involved $\left(Y_{1}, Y_{2}\right.$ or $\mathrm{Y}_{4}$ ), NPY has different, in part opposing effects on anxiety, fear and depression-related behaviors.

\section{Methods}

We combined site-specific deletion of NPY receptors and locally restricted over-expression of NPY receptor subtype-selective ligands with behavioral analysis to elucidate the contribution of the individual receptor subtypes in the modulation of emotional behavior.

\section{Results}

In Pavlovian fear conditioning, NPY knock-out (KO) mice display a dramatically accelerated acquisition of conditioned fear while fear extinction was impaired. Interestingly this phenotpye was only reproduced in mice lacking both the $Y_{1}$ and the $Y_{2}$ receptor. In $Y_{1}$ single $K O$ mice acquisition was moderately faster while fear extinction was delayed. Deletion of NPY and in particular of $Y_{2}$ receptors resulted also in a generalization of cued as well as context fear. Local over-expression of NPY by an rAAV vector in the basolateral amygdala delayed the acquisition and facilitated the extinction of fear, both in WT and NPY KO mice, emphasizing the crucial role of this area in NPYmediated fear acquisition and extinction. On the other hand, deletion of $\mathrm{Y}_{2}$ receptors in the central amygdala resulted in an increased expression and delayed extinction of conditioned fear, while there was no change in fear acquisition.

\section{Conclusions}

Taken together, our data demonstrate that NPY delays acquisition and reduces expression of conditioned fear whereas it promotes fear extinction. Both $Y_{1}$ and $Y_{2}$ receptors are involved in these processes. $Y_{1}$ receptors in the basolateral amygdala are modulating the acquisition and extinction of fear while $\mathrm{Y}_{2}$ receptors in the central amygdala are preferentially inhibiting the expression but facilitating the extinction of learned fear. Furthermore, $\mathrm{Y}_{2}$ receptors are crucially involved in the discrimination of fear-related stimuli.

\section{Acknowledgements}

Supported by the Austrian Science Fund (FWF, grant P 22830-B18).

\section{Author details}

${ }^{1}$ Institute of Pharmacology, Innsbruck Medical University, 6020 Innsbruck, Austria. Institute of Virology, Charité, Campus Benjamin Franklin, Free University of Berlin, 12203 Berlin, Germany. ${ }^{3}$ Neuroscience Research Program, Garvan Institute of Medical Research, Darlinghurst NSW 2010, Australia.

Published: 17 September 2012

doi:10.1186/2050-6511-13-S1-A87

Cite this article as: Tasan et al:: Neuropeptide $Y$ modulates fear and fear extinction in distinct nuclei of the amygdala. BMC Pharmacology and Toxicology 2012 13(Suppl 1):A87.

\footnotetext{
* Correspondence: ramon.tasan@i-med.ac.at

'Institute of Pharmacology, Innsbruck Medical University, 6020 Innsbruck, Austria

Full list of author information is available at the end of the article
} 